\title{
Taguchi's Method Analysis of an FMS Under Review-Period-Based Operational Controls: Identification of Control Periodicity
}

\author{
Felix T. S. Chan, Rajat Bhagwat, and S. Wadhwa
}

\begin{abstract}
Flexibility of flexible manufacturing systems (FMSs) has been considered as an effective tool to compete in the present manufacturing environment. Enormous research efforts have been made to harness the benefits of flexibility through superior control strategies. While modeling flexibility and control strategies, researchers have mostly assumed an information system that can provide real-time control. Literature qualitatively reports that the real-time control can be highly capital intensive and difficult to achieve. This paper focuses on FMS operating under reviewperiod (RP)-based control and presents a combined study of routing flexibility (RF), control strategies, and information system under Taguchi's method using simulation. RP-based control for FMS has been compared with real-time control. This paper contributes an approach for the decision maker to study the performance of an FMS operating under RP control and to identify the periodicity (time interval) of RP that will not deteriorate its performance in comparison to real-time control. It also helps the decision maker to reach a tradeoff between RP-based control and real-time control. The results show that RP-based control can be effectively implemented on an FMS having lower RF level. RP-based control can outperform real-time control with a superior control strategy and smaller RP size. The results under Taguchi's method suggest that the RF and control strategy should have maximum relative percentage contributions in FMS performance, whereas contribution of the RP (information system) should be minimum. Increasing the relative percentage contribution of the information system may deteriorate the performance of FMS. The information system is needed as a catalyst to facilitate the the contributions of other factors in improving the FMS performance and not its own contribution.
\end{abstract}

Index Terms-Control strategy, flexible manufacturing system (FMS), review period (RP), routing flexibility (RF) levels, Taguchi's method.

\section{INTRODUCTION}

$\mathbf{I}$ $\mathrm{N}$ RECENT years, there has been considerable interest in integration and flexible automation of manufacturing processes and controls. An important and central aspect of this trend is the changing roles of information system applications.

Manuscript received May 12, 2005; revised July 27, 2005 and September 10, 2005. This paper was recommended by Associate Editor R. G. Qiu.

F. T. S. Chan is with the Department of Industrial and Manufacturing Systems Engineering, University of Hong Kong, Kowloon, Hong Kong (e-mail: ftschan@hkucc.hku.hk).

R. Bhagwat is with the Department of Industrial and Manufacturing Systems Engineering, University of Hong Kong, Kowloon, Hong Kong, and also with the Department of Mechanical Engineering, J. N. V. University, Jodhpur 342 001, India (e-mail: rajat_bhagwat@hotmail.com).

S. Wadhwa is with the Department of Mechanical Engineering, Indian Institute of Technology-Delhi, New Delhi 110 016, India (e-mail: swadhwa@ mech.iitd.ernet.in).

Digital Object Identifier 10.1109/TSMCA.2006.886355
Information is the means of interfacing and integrating the entities of manufacturing systems, the mode of synchronizing the various entities, and the method of coordinating them in order to achieve the objectives [1].

According to Higgins and Browne [2], the monitoring function of a shop floor comprises three distinct elements, namely: 1) data capture; 2) data analysis; and 3) decision support. The data capture system collects all the relevant information from the shop floor, which is then "massaged" by the data analysis mechanism to produce real-time reports that aid the decisionmaking process. They further suggest that the role of production activity control is to provide the facility of real-time control in manufacturing. Researchers have advocated real-time control, particularly for shop floor of flexible manufacturing systems (FMSs)/computer-integrated manufacturing systems (CIMSs) (for shop-floor control, both FMS and CIMS can be considered as one and the same [3]). To achieve real-time control, the aforementioned three distinct elements of monitoring function and the decision making should be carried out in negligible time. FMS is considered to have a high level of decision automation with artificial intelligence and real-time control. It may not be possible for all manufacturing systems to have real-time capabilities. Furthermore, it may also not be necessary for all manufacturing systems to have the real-time control capabilities to harness the advantages, primarily for capital-intensive FMS, without having proper economic justification and performance level. FMS without real-time capabilities can look toward the review-period (RP)-based policy as one of the alternatives for shop-floor control. However, before implementing the RP policy, one should carefully analyze the advantages and limitations of it. The most important aspect for the decision maker is to identify the time horizon for its periodicity. The RP periodicity should be such that a tradeoff could be achieved between the advantages and disadvantages associated with real-time control and RP/non-real-time control. The RP-based policy may not be appreciated in the present age of information technology, but it may still be commercially more viable than real-time control.

Researchers have considered the RP mode to study the various aspects of FMS. For shop-floor control of FMS, most of the studies are oriented toward defining the RP-based dynamic scheduling or rescheduling approaches. Some studies have focused on the RP-based evaluation of performance measures and redefining of control strategies and production targets. In these studies, the impact of RP periodicity has not been considered or qualitatively mentioned. Furthermore, the effects 
of periodicity on the performance behavior of the physical and operating parameters of an FMS, such as flexibility and scheduling rules, have been ignored. This paper contributes an approach for the decision makers to analyze the performance of an FMS operating under RP-based control and to identify the periodicity of RP that does not deteriorate its effectiveness in comparison to real-time control. Initially, an analysis of simulation results has been suggested that identifies the productive and counterproductive operating zones of an FMS, through which a decision maker can ensure availment of the complete potentials of routing flexibility (RF) level present and control strategy enforced with respect to an information system (RP). Finally, analysis under Taguchi's method helps the decision maker to identify the periodicity of RP-based control and relative percentage contribution of each controlling parameter in FMS performance. Taguchi's method also provides an insight on the interactions between the control parameters.

This paper is organized as follows. Section II presents the background and motivation along with an overview of RP mode. Methodology has been outlined in Section III. Section IV defines the experimentation design for simulation model and Taguchi's method analysis. Results and discussions are organized in Section V, and conclusions are presented in Section VI.

\section{BACKGROUND AND MOTIVATION}

FMS can be defined as a manufacturing system having integrated and flexible resources (e.g., numerically controlled machines, automated guided vehicles for material handling, and automated inspections) that are soft controlled through a main controller having a required minimum level of decision automation. This type of manufacturing system is suitable for middle-volume and middle-variety manufacturing. The presence of flexibility and integration of resources makes FMS a competitive weapon in the present manufacturing environment. The information and communication system of FMS is considered as the nerve center, which integrates the islands of automation and provides vital inputs to control decisions. The control of all FMSs is highly contingent on the availability of information about the system's local and global status. In fact, there exists a symbiotic and intimate relationship between the shop-floor control system and the information management system [4]. The FMS control scheme assumes the ability of making decisions in real time based on real-time local and global information about the system. Patankar and Adiga [5] observe that in a CIM system, the integration is a timely availability of information required by each activity. Jorysz and Vernadat [6] describe information as the lifeblood of the CIM systems, the binding glue which ties together the various system functions and components, and as such, careful attention must be paid to its modeling.

According to Qiu et al. [7], the cost and long development cycle of shop-floor control systems and lack of appropriate system integration capability are some of the most challenging obstacles in deploying e-Manufacturing. Similarly, Pispa and Eriksson [8] conclude that the distinction between cost of information technology investments and potential benefits of implementing and using new information technology should be done at the conceptual level. It should be understood that the mere existence of an information technology application does not lead to the benefits. Recommending simulation as a tool for advance analysis, they argue that in a modeling approach, the alternative solutions should be kept in view as possible. We propose that RP-based monitoring can be one of the alternatives for control of FMS operation.

However, the design and operation of FMS are considered separately [9]. They involve intricate and interconnected decisions, which can result in maximizing the benefit from the system. They should be made simultaneously to achieve global optimization in the development of FMS. Park et al. [9] used regression analysis and compromised programming to model the design and operational parameters of an FMS and identified the suitable combination of these parameters under multiple objectives. However, they did not focus on the information system and flexibility levels as parameters of FMS. Harris [10] identified critical design, tactical, and operational factors for manufacturing system and used regression analysis to study the impact of these factors on performance. Information system requirements and flexibility were ignored from consideration as critical factors. Yurdakul [11] considered the cost aspect of various physical resources such as computer-aided design, computer-added engineering, computer-aided manufacturing, direct numerical control machines (DNC M/cs), and coordinate-measuring machines to evaluate the optimum design of CIMS. However, they did not consider the information system requirements or the operational aspects of it. Similarly, Duvivier et al. [12] presented an approach integrating simulation and optimization of manufacturing systems. Wu and Weng [13] proposed a multiagent scheduling method for a flexible job shop with the assumption of real-time decision making and information availability without mentioning it. Similarly, intelligent workstation/scheduler/FMS controllers with assumed real-time capabilities have been proposed by researchers [14]-[17]. According to Mcafee [18], the literature has reported that despite of rapidly growing and large investments in information technology, empirical research often has failed to identify tangible benefits associated with this investment, either in productivity or in other operational performance. The aforementioned views of researchers reflect that it is easy to invest in information technology and to assume real-time capabilities, but it may be difficult to achieve real-time control of the shop floor.

\section{A. Constraints in Real-Time Control}

A fully automated system requires that the information should be specified explicitly in computers. Furthermore, sufficient intelligence needs to be built into the system to infer this information. According to Veeramani et al. [4], the representation and manipulation of manufacturing-related information in a computer are not trivial tasks, and the level of complexity is more in manufacturing information management. This complexity stems from the heterogeneous nature of manufacturing information. Montazemi and Miltenburg [19] explain that in CIMS, the delays may take place in communication networks, i.e., the information transfer can be a time-consuming process. 
It depends on the magnitude of information and the nature and capacity of the communication medium and may lead to non-real-time control. It is important for resources to have the required competency to achieve the objective. According to Harzallah and Vernadat [20], there should be a clear differentiation between the acquired competencies and the required competencies of the resources.

Quéré et al. [21] identified communication time between the decision centers as one of the reasons for delays in schedules. They modeled communication time in reactive scheduling for complex system maintenance. According to Qiu et al. [7], lack of formal methods in providing a systematic approach for information integration in a manufacturing system leads to an ill-developed information system. The manufacturing organizations have very few comprehensive tools available to help in structured design and development of an information system [22], and any errors can adversely affect the company and can be very costly that the organization does not survive to attempt a second redesign. If proposed design can be tested and evaluated before its implementation, costly mistakes can be avoided. Harding et al. [22] further proposed that an information system modeling approach should help in gradual building of a progressive design, starting from a very simple and partial model. The RP can be a building block in a progressive design of real-time control.

The brief discussion above clearly outlines that the researchers have emphasized the timely availability of information and its importance in production control, but at the same time, some researchers have also acknowledged the difficulties in having real-time control. Non-real-time control has not been much of the focus of the researchers, although some of them have mentioned it qualitatively [4].

The concept of RP is not new, and it has been used by the researchers in different perspectives. Wainwright and Ridgway [23] described the RP in the context of the graphs with results and activities interrelated (GRAI) modeling approach as a time interval after which a decision maker compares the present state with that of the end state or goal and adjusts his actions accordingly. Chan and Chan [24] proposed a preemptive approach for dynamic scheduling for an FMS, which evaluates the performance measure on the basis of three objectives at every checkpoint (after a time interval) and accordingly selects a scheduling rule to improve the performance measure. Similarly, the RP has been focused on the scheduling/rescheduling/performance evaluation by the different researchers [19], [25]-[29]. According to Miguel and Shen [30], there may be a time interval between the change in value of a parameter inside the equipment (say a value of resistance) and its display on the controls. They presented the qualitative simulation study exhibiting this behavior.

The RP policy has been mostly considered by the previous researchers in the context of either monitoring the system's performance or implementing the control decision/activity or rescheduling the jobs, but not in the context of periodic updating of information in online controls. The impacts of RP periodicity on the performances of FMS parameters such as RF and control have not been the focus.

The RP policy may not require a high level of computerization and networking as is required in real-time data capturing.

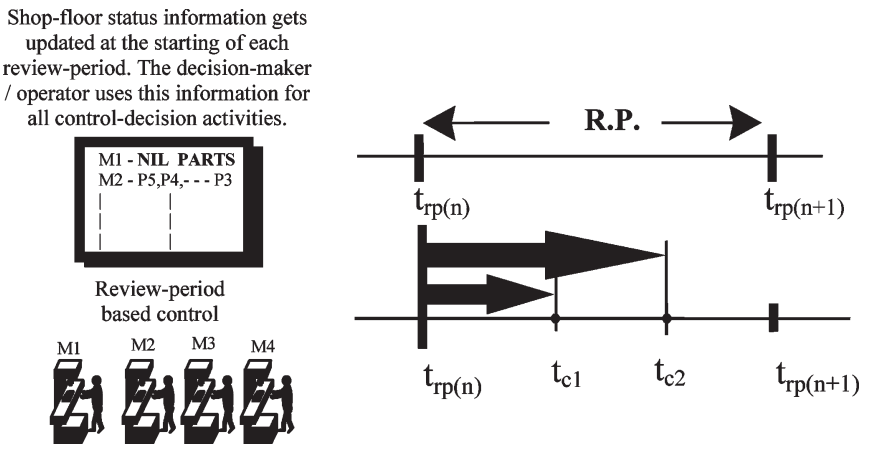

Fig. 1. Operator/decision maker has only to assess the available information based on the RP status information monitoring. Accordingly, control decisions are updated at the start of the RP, i.e., at time $t_{\mathrm{rp}(n)}$, and these control decisions will be used for all the decision events (say decision events at times $t_{c 1}$ and $t_{c 2}$ ) up to the next RP, i.e., up to time $t_{\mathrm{rp}(n+1)}$.

Hence, it may be cost effective. In our opinion, the study of RP-based control systems will motivate pragmatic research for companies that find the investments in a highly computerized FMS/CIMS too prohibitive and risky. Phased development of FMS through stepped investments in flexibility, decision automation, information integration, and operation control may be a useful alternative. The system designer/controller would like to invest in these key factors only to the required levels.

A typical industrial motivation can be expressed as a question on IT in manufacturing as follows: is an expensive online system with real-time control more desirable in view of its capabilities, or is some cheaper system with RP-based monitoring more justifiable in a given scenario? The relevant research issues are to study the roles of flexibility and control strategy in an FMS operating under RP-based monitoring. It is also important to study the nature of degradation of the performance in a given FMS under the RP mode. This paper attempts to address these issues. Computer simulation has been used as a tool to facilitate modeling of various operating conditions. Taguchi's method has been used for postanalysis of simulation results.

\section{B. RP Mode}

In RP-based monitoring, the status information is updated after a fixed interval of time, i.e., at the start of each RP. This updated information is then used for all decision-making activities taking place during the RP. A decision maker/operator has access to the information that has been updated at the start of the RP. This RP-based information will be used by the decision maker for all control decision-making activities during the RP. As shown in Fig. 1, consider an activity taking place at time $t_{c 1}$, which requires a control decision making (say a sequencing decision). The decision maker/operator will use the status information that has been updated at the start of the RP, i.e., at time $t_{\operatorname{rp}(n)}$ for decision making. Similarly, for any other decision-making activities during this RP (say at time $t_{c 2}$ ), the decision maker will use the same status information that has been updated at the start of the RP, i.e., at time $t_{\mathrm{rp}(n)}$. Thus, the same status information will be used for all decision-making activities during the RP. 


\section{Methodology}

To study the FMS operating under the RP-based control, the advantage of simulation modeling has been taken into consideration. With analytical modeling, it may be difficult (or practically impossible) to model FMS with its entire operating and physical characteristics in a dynamic operating environment. To simplify the analytical modeling approach, some unrealistic assumptions may be required. This may not provide the actual image of FMS performance. Furthermore, an analytical modeling will be more complex when considering dynamic heterogeneous operating environment of FMS and time aspect (periodicity) in control. With these views, a simulation modeling has been preferred to study the FMS operating under RP. In this paper, the steps in the methodology are listed below and thereafter briefly described. The experimentation specifications for the first two steps (considered in this paper) are explained in Section IV.

1) Defining the parameters of an FMS to be studied. It is important to identify and consider the key parameters of an FMS for study. There may be other parameters having either minor or negligible impact on the performance. The modeling of such parameters only makes a model more complex and difficult to study. These parameters may also obstruct the actual impact of the key parameters.

2) Defining a configuration of an FMS and its simulation modeling.

3) Analysis of simulation results to study the performance of the configured FMS operating under the RP mode and the impact of RP periodicity. The simulation results have been analyzed for various levels of RF, control strategies, and RP periodicity. This analysis can help the decision maker to identify the productive and counterproductive operating zones of an FMS. Furthermore, the analysis can also help in identifying whether there have been any advantages of having RF, superior control strategy, and information system.

4) Analysis of simulation results under Taguchi's method. This analysis helps the decision maker to identify the suitable periodicity of the RP and the contribution of each factor on the performance of FMS. It also helps in identifying the influence of one factor on the performance of other factors and whether this mutual influence helps in improving or deteriorating the performance.

The performance of an FMS depends on its physical and operating parameters. The physical parameters are as follows: number of machines/resources available, types of flexibility present, range of revolutions per minute and feeds available (these decide the processing time), numbers of pallets and fixtures, tool slots, etc., which cannot be changed once a system has been installed. Operating parameters refer to control strategies (including variable settings of some physical parameters) that are used (on the basis of the current status information of system) to operate the physical system in the best possible way to achieve the objective. The information system facilitates the decision maker by providing status information as input to control decisions such as sequencing decisions (part selection), dispatching decisions (machine selection), transportation vehicle selection, tool selection on machine, etc. Some of the parameters such as number of pallets or fixtures, job's transportation from a machine, tool selection/changing time on a machine, etc., affect a job completion time on a machine. These can be considered as included in the total processing time, thereby avoiding complex modeling.

According to Shewchuk and Moodie [31], flexibility has been seen as a principal mechanism for surviving in the present manufacturing environment. An FMS is characterized by its flexibility. Sarker et al. [32] have presented a classification for the types of manufacturing flexibility as follows: machine flexibility, process flexibility, RF, expansion flexibility, job flexibility, design flexibility, material handling flexibility, setup time flexibility, and volume flexibility. Similarly, classifications for the types of flexibility have been proposed by the researchers from different views [33], [34]. Although the types of flexibility have been defined from different views and accordingly given different names, the origin of these flexibilities may be from common sources. Browne et al. [33] have described eight types of flexibility in connection with FMS, of which machine flexibility and RF have been considered to be important. These two flexibilities lay the foundation for other manufacturingrelated flexibilities. The other types of flexibility can be derived in the FMS when machine flexibility and RF are present. If an FMS has machine flexibility for a given part family or a given product range, then out of these two types of flexibility, the RF level only remains as one of the controlling parameters of the shop floor. In this paper, RF has been considered as one of the controlling parameters. The availability of RF can also be considered as the presence of other types of derived flexibility in the system.

As stated earlier, it is expedient to use simulation as a modeling tool and follow the steps of a typical simulation study. A single hypothetical manufacturing system model that can capture the logic of the different levels of RF and control strategies has been configured. One of the major motivations has been to develop a demonstrative model to increase the perception of both the researchers and the practitioners. Thus, it is felt that the defined system may focus on a few key factors and should not be too large and too complex. In a sense, interest was in the typical size and complexity of the system that has been widely researched.

One of the objectives of this paper is to study an FMS operating under non-real-time RP-based control system and underline the performance of FMS with varying length of RP and compare it with real-time control system. It is important for the designer/decision maker of FMS to understand how critical is the flexibility and its level and control strategy for the performance of system. What are their relative percentage contributions on the performance of a given FMS? How do the contributions of flexibility and its level as well as the control strategies change with the changes in RP periodicity? This will provide an insight to the decision maker to identify the periodicity of RP to control a given FMS.

Researchers have used various statistical tools to study the FMS from different views [9], [10], [14], [35]-[37]. To have more insight on the simulation results, these will be further analyzed under Taguchi's method. The said method will be 
used to study the impact of RP-based control in comparison to real-time control. This also outlines a method that would help the decision maker to gain a quick insight about the relative importance of design and control factors. This approach provides a convenient and efficient way to study the individual factors and their interactions simultaneously. In Taguchi's method, the results of the experiments are analyzed to achieve one or more of these three objectives [38]: 1) to establish the best or the optimum condition for a product or a process; 2 ) to estimate the contribution of the individual factors and their interactions; and 3) to estimate the response under the optimum conditions. Here, we use Taguchi's method to focus more on the second objective, i.e., to estimate the contributions of the individual factors and their interactions to have an insight on the behavior of FMS control factors. The sample results will be discussed for the remaining two objectives. The operational control factors considered for study under Taguchi's method are: 1) RF level; 2) RP time interval; 3 ) sequencing rule (SR); and 4) dispatching rule (DR) for a given FMS and the interactions between them $(\mathrm{RF} \times \mathrm{RP}, \mathrm{RF} \times \mathrm{SR}, \mathrm{RF} \times \mathrm{DR}, \mathrm{SR} \times \mathrm{DR}, \mathrm{SR} \times \mathrm{RP}$, and $\mathrm{DR} \times \mathrm{RP}$ ), each at two levels.

Taguchi's experimental design paradigm is based on the technique of matrix experiments [39]. Experimental matrices are essentially special orthogonal arrays (OAs), which efficiently allow the simultaneous study of several process parameters and their interactions. The term interaction is used when one factor influences the performance of other factor(s). Taguchi's method determines the relationships when interacting the columns of OA. These relationships are present in standard tables called triangular table of interactions and contain information about the interactions of the various columns of OA. The process of experimental design includes selecting a suitable $\mathrm{OA}$, assigning the factors and their interactions to the appropriate columns of the OA, and determining the conditions for experiments from the rows of OA. The results of the experiments carried out according to Taguchi's method are analyzed by using analysis of variance (ANOVA). The contribution of each factor and the interactions between the factors can be quantitatively determined by using ANOVA [40].

The success of Taguchi's method lies in the identification of the key factors and their levels, which influence the performance measure. According to Logothetis and Wynn [41], if all the major factors that can influence the performance are not considered under Taguchi's method, then the study may not provide a clear representation. To identify that all the major factors have been considered under Taguchi's method study, Logothetis and Wynn [41] suggest that the percentage contribution of pooled errors in the ANOVA should not be more than $15 \%-20 \%$.

\section{EXPERIMENTATION DESIGN}

Simulation modeling has been widely used for the purpose of designing, planning, scheduling, and controlling of manufacturing system. Simulation is synonymous with imitation. A simulation model may be defined as a concise framework for the analysis that facilitates imitating the behavior of the system over a period of time. In contrast to mathematical models, simulation models do not need explicit mathematical functions to relate the variables. Therefore, they are suitable for representing complex system to have an image of the real system. It is especially true for flexible systems where online control strategies are employed.

According to Darabi et al. [42], FMS consists of a network of activities with deterministic times. In this paper, a deterministic FMS, which consists of six flexible machines with input buffers, has been considered. There are six part types that follow alternative processing routes in the system. The numbers of operations required for processing the part type have been taken as four to six. The minimum and maximum processing times have been considered as 35 and 100 units, respectively, with the average processing time of operations as 55 units. The makespan for processing a product mix of 300 parts has been modeled as performance measure using deterministic simulation.

The system is considered to have RF. The level of RF can be varied within the existing machines. The parts can be processed on the alternative machines depending on the level of RF present in the system. The RF concept (similar to Chan [43]) can be described as follows: $\mathrm{RF}=0$ means that there is exactly one machine for an operation on a given part, i.e., there are zero alternatives. $\mathrm{RF}=1$ implies that there are two possible machines for processing the same operation, i.e., there is exactly one more alternative machine (other than the machine that is available at $R F=0$ ) for any operation on any part. $R F=2$ implies that there are three possible machines for processing the same operation, i.e., there are exactly two more machines available for processing the same operation (other than the machine that is available at $\mathrm{RF}=0)$. Similarly, $\mathrm{RF}=3$ and $\mathrm{RF}=4$ imply that three and four more alternative machines are available, respectively, for any part operation.

The parts can be routed through the different machines for processing depending on the level of RF available in the system. Each machine has an associated sequencing decision point and a dispatching decision point attached to it. The decision system invokes the control decisions at these decision points. A decision point takes the decision for selection of a part or a machine according to the implemented control strategy and available status information.

The machine is selected by the dispatching decision point for the next operation from the available alternative machines. The number of alternative machines available depends on the level of RF present in the system. The RF level has been varied from no alternative machine $(\mathrm{RF}=0)$ to four more alternative machines $(\mathrm{RF}=4)$ available for the processing of the next operation. Simulation results were obtained for different combinations of RF levels, RP periodicity, SRs, and DRs.

To further study the simulation results under Taguchi's method, we have selected the variation of factors at two levels. Two-level combinations under Taguchi's method provide a linear study of the assumed factors with a good approximation. The advantage with the two levels is that the numbers of experiments to be conducted are less and the study of interactions between the factors is not too complicated. The other advantage of using two levels is that it helps in studying the influence of individual factors by varying only the upper level (or the lower 
TABLE I

FACTOR LEVEl COMBINATIONS CONSIDERED FOR TAGUCHI's METHOd ExPERIMENTATION

\begin{tabular}{|c|c|c|c|c|c|}
\hline Factor levels & Factor levels & Factor levels & Factor levels & Factor levels & Factor levels \\
\hline \multicolumn{6}{|c|}{$\begin{array}{l}\text { Routing flexibility levels are: } \\
\text { and } R F=2 \text {, (iii) } R F=0 \text { and } R F=3 \text {, and (iv) } R F=0 \text { and } R F=4 \text {, } \\
\text { nns have been experimented with each set of routing flexibility levels. }\end{array}$} \\
\hline $\begin{aligned} \mathrm{SR}= & \mathrm{SPT}- \\
& \mathrm{MBPT}\end{aligned}$ & $\begin{aligned} \mathrm{SR}= & \text { SPT }- \\
& \text { MBPT }\end{aligned}$ & $\begin{aligned} \mathrm{SR}= & \text { SPT }- \\
& \text { MBPT }\end{aligned}$ & $\begin{aligned} \mathrm{SR}= & \text { SPT }- \\
& \text { MBPT }\end{aligned}$ & $\begin{aligned} \mathrm{SR}= & \text { SPT }- \\
& \text { MBPT }\end{aligned}$ & $\begin{aligned} \mathrm{SR}= & \text { SPT }- \\
& \text { MBPT }\end{aligned}$ \\
\hline $\begin{aligned} \mathrm{DR}= & \text { MINQ- } \\
& \text { MWTQ }\end{aligned}$ & $\begin{aligned} \mathrm{DR}= & \text { MINQ- } \\
& \text { MWTQ }\end{aligned}$ & $\begin{aligned} \mathrm{DR}= & \text { MINQ- } \\
& \text { MWTQ }\end{aligned}$ & $\begin{aligned} \mathrm{DR}= & \text { MINQ- } \\
& \text { MWTQ }\end{aligned}$ & $\begin{aligned} \mathrm{DR}= & \text { MINQ- } \\
& \text { MWTQ }\end{aligned}$ & $\begin{aligned} \mathrm{DR}= & \text { MINQ- } \\
& \text { MWTQ }\end{aligned}$ \\
\hline$R P=0-4$ & $R P=0-10$ & $R P=0-20$ & $R P=0-35$ & $0-50$ & $R P=0-65$ \\
\hline $\begin{array}{l}\text { Interactions } \\
\text { between above } \\
\text { factors. }\end{array}$ & $\begin{array}{l}\text { Interactions } \\
\text { between above } \\
\text { factors. }\end{array}$ & $\begin{array}{l}\text { Interactions } \\
\text { between above } \\
\text { factors. }\end{array}$ & $\begin{array}{l}\text { Interactions } \\
\text { between above } \\
\text { factors. }\end{array}$ & $\begin{array}{l}\text { Interactions } \\
\text { between above } \\
\text { factors. }\end{array}$ & $\begin{array}{l}\text { Interactions } \\
\text { between above } \\
\text { factors. }\end{array}$ \\
\hline
\end{tabular}

level) of that factor and keeping the levels of all other factors constant. For two-level factors, OA $L_{16}$ was considered to study four factors and six interactions between them.

To study the impact of control strategy, the two levels of the SRs and DRs have been modeled. The different control strategies are a combination of the SRs and DRs. The SRs used are SPT (select the part for next processing that has the "shortest processing time" on the machine) and MBPT (select the part for next processing that has the "maximum balance processing time" left), whereas the DRs used are MINQ (select a machine for the next operation that has the "minimum queue" at the input buffer) and MWTQ (select a machine for the next operation that has the "minimum waiting time in queue," i.e., the sum of processing times of parts waiting in the input buffer of the machine). According to Shnits et al. [44], the recent 100 research studies (1988-2001) of complex manufacturing systems such as FMS and job shop have considered SPT SR as the most popular for the studies. In this paper, one of the objectives is to study the performance of alternative SRs under the RP control at different RF levels and not to find out an optimum performing SR; therefore, the two rules have been selected to study their performance.

Under Taguchi's method, experiments have been conducted for varying RF levels and RP periodicity. The RF level combinations have been as follows: a) $R F=0$ (no $R F$ ) and $R F=1$; b) $\mathrm{RF}=0$ and $\mathrm{RF}=2 ; \mathrm{c}) \mathrm{RF}=0$ and $\mathrm{RF}=3$; and $\mathrm{d}) \mathrm{RF}=0$ and $\mathrm{RF}=4 . \mathrm{RF}=0$ and $\mathrm{RF}=1$ shows the introduction of $\mathrm{RF}$ in the system, whereas $R F=0$ and $R F=4$ shows the highest level of RF in the system.

For RP, six time intervals have been considered for study in comparison with real-time control. For real-time control, the RP time interval will be zero (i.e., $\mathrm{RP}=0$ ). The time intervals of RP have been selected on the basis of the processing time of the jobs. The minimum processing time of a job has been 35 units, whereas the maximum processing time has been 100 units, with the average processing time of approximately 55 units. Under Taguchi's method experimentation, the six level combinations of RP with real-time control considered for study were: a) $\mathrm{RP}=0$ (real time) and $\mathrm{RP}=4 ; \mathrm{b}) \mathrm{RP}=0$ and $\mathrm{RP}=10 ; \mathrm{c}) \mathrm{RP}=0$ and $\mathrm{RP}=20 ; \mathrm{d}) \mathrm{RP}=0$ and $\mathrm{RP}=35$ (equal to the minimum processing time); e) $\mathrm{RP}=0$ and $\mathrm{RP}=50$ (almost equal to the average processing time); and f) $\mathrm{RP}=0$ and $\mathrm{RP}=65$ (more than the average processing time). These six level combinations of RP have been experimented one by one for the four sets of RF. Table I shows the level combinations of factors considered under Taguchi's method experimentation, whereas Table II shows their sample level combinations in OA $L_{16}$. The RF level combination in Table II is $\mathrm{RF}=0$ and $\mathrm{RF}=1$. In Table II, Columns $1,2,4$, and 11 of OA $L_{16}$ have been allocated to four factors: RF, SR, DR, and RP, respectively. Columns 3, 5, 6, 9, 10, and 15 have been allocated to the interactions between the four factors. Columns 7, 8, 12, 13, and 14 have been left unallocated because Columns $7,8,13$, and 14 capture the interactions with Column 12, which has been also unallocated. The last three columns of Table II show the sample makespan results of the simulation experiments carried out under Taguchi's method for different level combinations of RP. Similarly, Table III shows the experimentation combinations and sample simulation results for $\mathrm{RF}$ level combination $\mathrm{RF}=0$ and $\mathrm{RF}=4$.

\section{A. Assumptions}

This paper has focused on the study of the impact of RP mode on the performance of the FMS and its control parameters. Some assumptions have been intentionally made to bring out the impact of RP periodicity exclusively on the performances of FMS factors. In the present comparative study, any such conditions that: 1) can have nonuniform deteriorating effect on the performance of FMS and 2) may not be under the control of decision maker/controller have been avoided. For these situations, ideal conditions have been assumed to help in extracting the impact of RP only. The following assumptions have been made for modeling the simulation model.

1) It has been assumed that raw materials for jobs are always available. The availability of raw materials is not a deterministic phenomenon by nature and may have a nonuniform effect. Our objective is to study the comparative effect of RP periodicity; hence, the raw material has been assumed available for providing similar situations under different periodicities. Future research is expected to cover this dimension of the nonavailability of raw materials. 
TABLE II

OA $L_{16}$ FOR EXPERIMENTATION SET With RF $=0-1$ AND RP $=0-4,0-35$, AND 0-65. The LAST Three COLUMNS INDICATE THE MaKespan Results of Simulation Experiments Under Taguchi's Method at AFOREMEnTioned LeVels of RP

\begin{tabular}{|c|c|c|c|c|c|c|c|c|c|c|c|c|c|c|c|c|c|c|}
\hline COLMN $\rightarrow$ & 1 & 2 & 3 & 4 & 5 & 6 & 7 & 8 & 9 & 10 & 11 & 12 & 13 & 14 & 15 & \multicolumn{3}{|c|}{ Result (Make-span) } \\
\hline $\begin{array}{l}\text { FACTS } \rightarrow \\
\text { EXP. No }\end{array}$ & $\mathrm{RF}$ & SR & $\begin{array}{l}\text { RF } \\
X \\
\text { SR }\end{array}$ & $\mathrm{DR}$ & \begin{tabular}{|l|}
$\mathrm{RF}$ \\
$\mathrm{X}$ \\
$\mathrm{DR}$ \\
\end{tabular} & \begin{tabular}{l|}
$\mathrm{SR}$ \\
$\mathrm{X}$ \\
$\mathrm{DR}$
\end{tabular} & - & - & $\begin{array}{l}\mathrm{SR} \\
\mathrm{X} \\
\mathrm{RP}\end{array}$ & $\begin{array}{l}\mathrm{RF} \\
\mathrm{X} \\
\mathrm{RP}\end{array}$ & $\mathrm{RP}$ & - & - & - & $\begin{array}{l}\text { DR } \\
X \\
\text { RP }\end{array}$ & $\begin{array}{l}\mathrm{RP}= \\
0 \& \\
4\end{array}$ & \begin{tabular}{|l}
$\mathrm{RP}=$ \\
$0 \&$ \\
35
\end{tabular} & $\begin{array}{l}\mathrm{RP}= \\
0 \& \\
65\end{array}$ \\
\hline 1 & $\mathrm{RF}=0$ & SPT & 1 & MINQ & 1 & 1 & - & - & 1 & 1 & $\mathrm{RP}=0$ & - & - & - & 1 & 16057 & 6057 & 16057 \\
\hline 2 & $\mathrm{RF}=0$ & SPT & 1 & MINQ & 1 & 1 & - & - & 2 & 2 & $\mathrm{RP}=4-65$ & - & 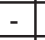 & - & 2 & 15828 & 15818 & 16100 \\
\hline 3 & $\mathrm{RF}=0$ & SPT & 1 & MWTQ & 2 & 2 & - & - & 1 & 1 & $\mathrm{RP}=0$ & - & - & - & 2 & 16057 & 6057 & 16057 \\
\hline 4 & $\mathrm{RF}=0$ & SPT & 1 & MWTQ & 2 & 2 & - & - & 2 & 2 & $R P=4-65$ & - & - & - & 1 & 15828 & 5818 & 16100 \\
\hline 5 & $\mathrm{RF}=0$ & MBPT & 2 & IINQ & 1 & 2 & - & - & 1 & 2 & $\mathrm{RP}=4-65$ & - & - & - & 2 & 16037 & 6247 & 16300 \\
\hline 6 & $\mathrm{E}=0$ & MBPT & 2 & INQ & 1 & 2 & - & - & 2 & 1 & $\mathrm{RP}=0$ & - & - & - & 1 & 16286 & 16286 & 16286 \\
\hline 7 & $\mathrm{RF}=0$ & MBPT & 2 & MWTQ & 2 & 1 & - & - & 1 & 2 & $R P=4-65$ & - & - & - & 1 & 16037 & 16247 & 16300 \\
\hline 8 & $\mathrm{RF}=0$ & MBPT & 2 & MWTQ & 2 & 1 & - & - & 2 & 1 & $\mathrm{RP}=0$ & - & - & - & 2 & 16286 & 16286 & 16286 \\
\hline 9 & $\mathrm{RF}=1$ & SPT & 2 & MINQ & 2 & 1 & - & - & 2 & 1 & $\mathrm{RP}=4-65$ & - & - & - & 2 & 15408 & 15655 & 16322 \\
\hline 10 & $\mathrm{RF}=1$ & SPT & 2 & MINQ & 2 & 1 & - & - & 1 & 2 & $\mathrm{RP}=0$ & - & - & - & 1 & 15516 & 15516 & 15516 \\
\hline 11 & $\mathrm{RF}=1$ & SPT & 2 & MWTQ & 1 & 2 & - & - & 2 & 1 & $\mathrm{RP}=4-65$ & - & - & - & 1 & 15648 & 15903 & 16406 \\
\hline 12 & $\mathrm{RF}=1$ & SPT & 2 & MWTQ & 1 & 2 & - & - & 1 & 2 & $\mathrm{RP}=0$ & - & - & - & 2 & 15683 & 15683 & 15683 \\
\hline 13 & $\mathrm{RF}=1$ & MBPT & 1 & MINQ & 2 & 2 & - & - & 2 & 2 & $\mathrm{RP}=0$ & - & - & - & 1 & 15698 & 15698 & 15698 \\
\hline 14 & $\mathrm{RF}=1$ & MBPT & 1 & MINQ & 2 & 2 & - & - & 1 & 1 & $R P=4-65$ & - & - & - & 2 & 16047 & 15988 & 16386 \\
\hline 15 & $\mathrm{RF}=1$ & MBPT & 1 & MWTQ & 1 & 1 & - & - & 2 & 2 & $\mathrm{RP}=0$ & 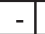 & - & - & 2 & 15924 & 15924 & 15924 \\
\hline 16 & $\mathrm{RF}=1$ & MBPT & 1 & MWTQ & 1 & 1 & - & 1 & 1 & 1 & $\mathrm{RP}=4-65$ & - & - & - & 1 & 16147 & 16130 & 16450 \\
\hline
\end{tabular}

TABLE III

OA $L_{16}$ FOR EXPERIMENTATION SET With RF $=0-1$ AND RP $=0-4,0-35$, AND 0-65. The Last ThreE Columns INDiCATE THE MAKESPAN RESUlts of SimUlation EXPERIMENTS Under TAGUCHI's METHOD AT AFOREMENTIONED LEVELS OF RP

\begin{tabular}{|c|c|c|c|c|c|c|c|c|c|c|c|c|c|c|c|c|c|c|}
\hline $\mathrm{COL}$ & 1 & 2 & 3 & 4 & 5 & 6 & 7 & 0 & 9 & 10 & 11 & & 13 & 14 & 15 & \multicolumn{3}{|c|}{ Result (Make-span) } \\
\hline $\begin{array}{l}\text { FACTS } \rightarrow \\
\text { EXP. No } \\
\downarrow\end{array}$ & $\mathrm{RF}$ & SR & $\begin{array}{l}\text { RF } \\
X \\
\text { SR }\end{array}$ & $\overline{\mathrm{DR}}$ & \begin{tabular}{l|}
$R F$ \\
$X$ \\
$D R$
\end{tabular} & $\begin{array}{l}\text { SR } \\
X \\
\text { DR }\end{array}$ & & - & \begin{tabular}{l|}
$\mathrm{SR}$ \\
$\mathrm{X}$ \\
$\mathrm{RP}$
\end{tabular} & \begin{tabular}{|l|}
$\mathrm{RF}$ \\
$\mathrm{X}$ \\
$\mathrm{RP}$ \\
\end{tabular} & $\overline{R P}$ & & - & - & \begin{tabular}{|l}
$\mathrm{DR}$ \\
$\mathrm{X}$ \\
$\mathrm{RP}$
\end{tabular} & $\begin{array}{l}\mathrm{RP}= \\
0 \& \\
4\end{array}$ & $\begin{array}{l}\mathrm{RP}= \\
0 \& \\
35 \\
\end{array}$ & $\begin{array}{l}\mathrm{RP}= \\
0 \& \\
65\end{array}$ \\
\hline 1 & $\overline{\mathrm{F}=0}$ & $\overline{\mathrm{PT}}$ & 1 & MINO & 1 & 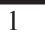 & - & - & 1 & 1 & $\mathrm{RP}=0$ & & 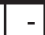 & - & 1 & 16057 & 16057 & 16057 \\
\hline 2 & $\mathrm{~F}=0$ & PT & 1 & 2 & 1 & 1 & - & - & 2 & 2 & $R P=4-65$ & & 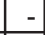 & - & 2 & 15828 & 15818 & 16100 \\
\hline 3 & $\mathrm{~F}=0$ & PT & 1 & WTQ & 7 & 5 & 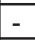 & - & 1 & 1 & $\mathrm{RP}=0$ & & 4 & - & 2 & 16057 & 16057 & 16057 \\
\hline 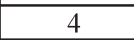 & $\mathrm{F}=0$ & PT & 1 & $\mathrm{Q}$ & 2 & - & 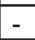 & & 2 & 2 & $R P=4-65$ & & & - & 1 & 15828 & 15818 & 16100 \\
\hline$=$ & $\mathrm{RF}=0$ & IBPT & 2 & IIN & 1 & 2 & - & & 1 & 2 & $R P=4-65$ & & & - & 2 & 16037 & 16247 & 17627 \\
\hline 6 & $\mathrm{RF}=0$ & BPT & 2 & & 1 & 2 & - & - & 2 & 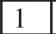 & $\mathrm{RP}=0$ & & & - & 1 & 16286 & 16286 & 16286 \\
\hline 7 & $\mathrm{RF}=0$ & $\overline{\mathrm{BPT}}$ & 2 & & 2 & 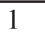 & - & $\begin{array}{ll}- \\
\end{array}$ & 1 & 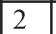 & $\mathrm{RP}=4-$ & & & - & 1 & 16037 & 16247 & 17627 \\
\hline 8 & $\mathrm{~F}=0$ & BPT & 2 & & 2 & 1 & - & & 2 & 1 & $\mathrm{RP}=0$ & & & - & 2 & 16286 & 16286 & 16286 \\
\hline 9 & $\overline{\mathrm{F}=4}$ & PT & 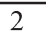 & & & 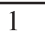 & - & & 2 & 1 & $R P=4-65$ & & -1 & - & 2 & 14794 & 16693 & 17799 \\
\hline 10 & $\mathrm{~F}=4$ & PT & 2 & & 2 & 1 & - & - & 1 & 2 & $\mathrm{RP}=0$ & & 4 & - & 1 & 14384 & 14384 & 14384 \\
\hline & $\mathrm{F}=4$ & PT & 2 & & 1 & 2 & $1-$ & - & 2 & 1 & $\mathrm{RP}=4-65$ & & - & - & 1 & 15221 & 16991 & 18100 \\
\hline & $\mathrm{F}=4$ & PT & 2 & & 1 & 2 & - & - & 1 & 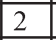 & $\mathrm{RP}=0$ & & - & - & 2 & 14642 & 14642 & 14642 \\
\hline 13 & $\mathrm{~F}=4$ & $\overline{B P T}$ & 1 & & 2 & -2 & - & - & 2 & 2 & $\mathrm{RP}=0$ & & - & - & 1 & 15351 & 15351 & 15351 \\
\hline 14 & $\mathrm{~F}=4$ & $\overline{B P T}$ & 1 & & 2 & 2 & - & - & 1 & 1 & $R P=4-65$ & & 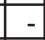 & - & 2 & 15426 & 16770 & 17900 \\
\hline 15 & $\mathrm{RF}=4$ & ABPT & 1 & $\mathrm{~N}$ & 1 & 1 & - & - & 2 & 2 & $\mathrm{RP}=0$ & & - & - & 2 & 15556 & 15556 & 15556 \\
\hline 16 & $\mathrm{RF}=4$ & MBPT & 1 & MWTQ & 1 & 1 & - & - & 1 & 1 & $\mathrm{RP}=4-65$ & & - & - & 1 & 16126 & 16923 & 18200 \\
\hline
\end{tabular}

2) Preemption is not allowed (i.e., operations that begin the processing are completed without interruption).

3) Machines do not break down, or machines never fail to perform a required task for lack of operator, tool, or other requirements. The machine breakdown is also not a deterministic phenomenon and may have a nonuniform impact under different situations. Furthermore, the machine breakdown is expected to result in further deterioration of performance; hence, it is avoided.

4) Due dates are not considered because makespan has been the performance measure.

5) Processing times are deterministic.

6) Each machine can process only one operation at a time.

7) Setup time is sequence independent and is included in the processing time.
8) Transportation times between the facilities are included in the processing time.

9) Jobs are never rejected due to inspections.

\section{RESUlts AND Discussions}

First, the analysis of the simulation results will be presented, which will provide an insight on the information system and the performance of a given FMS. Then, simulation results under Taguchi's method are discussed to provide a quantitative view on the simulation results.

\section{A. Analysis of Simulation Results}

Fig. 2 shows the makespan performance of a given FMS at different periodicities of RP and various levels of RF with 


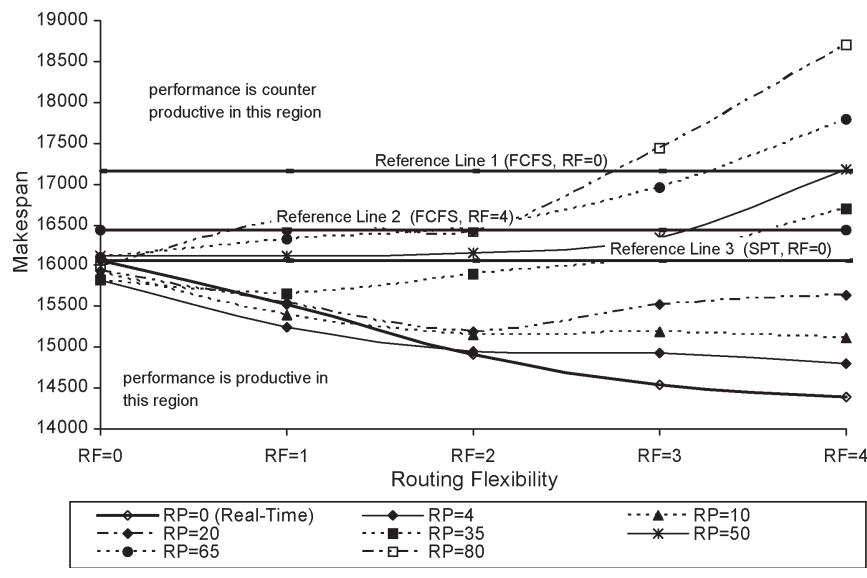

Fig. 2. Makespan performance for various levels of RF at different time intervals of RP with SPT as SR and MINQ as DR.

SPT as SR and MINQ as DR. In Fig. 2, three reference lines are indicated and named as reference line 1, reference line 2, and reference line 3 . Reference line 1 represents the makespan performance of a given $\mathrm{FMS}$ at $\mathrm{RF}=0$ (i.e., no $\mathrm{RF}$ in the system) and SR as first come first served (FCFS). As no RF is present, no DR is required. When FCFS SR is used and the system does not have any RF, no control decisions (hence, "no information system") are required. The operators/machines will process the parts in their incoming sequence of FCFS. There is no control decision-making activity on the shop floor. This can be referred as the minimum/worst condition of the performance of a given FMS. The makespan performance of a given FMS should not deteriorate below this performance at any point of time. Reference line 1 in Fig. 2 represents the makespan performance under this condition. The makespan performance of a given FMS should always be on or below reference line 1 . If makespan performance falls above this line due to any reason(s) (use of improper control strategy or counterproductiveness of flexibilities or information system), then it indicates a negative influence of the control parameter(s) on the performance of FMS. The decision maker should look at and analyze the control parameter(s) to eliminate this negative effect on the performance. At least, a decision maker can switch on to the conditions of no RF and FCFS SR to minimize this negative effect.

Reference line 2 in Fig. 2 represents a makespan performance with $\mathrm{RF}=4$ (maximum available RF), SR as FCFS, and DR as MINQ. When the system has an RF, then dispatching decision making (machine selection for next operation) is required. Therefore, certain information (and hence information system) is required to evaluate the alternatives available by the virtue of RF. In this paper, it has been considered as a non-realtime, slow, and cost-effective information system with RP of 50 units of time (approximately equal to the average processing time of a job) available for dispatching decisions. SR is FCFS; hence, no information is required. This has been assumed as a condition in which there is no role of information system and performance improvement is only due to the presence of RF. Reference line 2 represents this performance. This can be assumed as the minimum/worst performance at $\mathrm{RF}=4$.
Therefore, it can be said that any makespan performance falling between reference line 1 and reference line 2 will have positive benefits of available RF only and no positive contributions of information system or superior control strategy. On the contrary, at $\mathrm{RF}=4$, if performance falls above reference line 2 , then the information system and/or the control strategy may have a negative impact on performance to reduce the benefits of RF. The fraction (segment) of makespan that is above reference line 2 should be considered as a contribution of the information system and/or control strategy in the deterioration of performance. The decision maker should review the control strategy enforced and the information system when makespan performance falls above reference line 2, or at least, the decision maker can switch to FCFS SR to eliminate this negative effect. Similarly, reference line 2 for different levels of RF can be drawn. This can help in identifying the benefits attached with each level of RF.

Reference line 3 represents the makespan performance of a given FMS at no RF $(\mathrm{RF}=0)$ with superior control strategy (SPT SR) and real-time information system. The region between reference line 2 and reference line 3 can be assumed as the absolute contribution from the combination of realtime control (information system) and a given superior control strategy. The position of reference line 3 may vary with the type of control strategy enforced.

At higher RF levels (above RF $=0$ ) of the studied FMS, if makespan performance falls above reference line 3 with superior control strategy (like SPT SR), then the fraction (portion) of makespan performance that is above reference line 3 represents the contribution of a poor information system in deteriorating the FMS performance and needs to be improved, and if operating with RP policy, then the size of RP needs to be reduced.

At higher RF levels of the studied FMS, if reference line 3 lies above reference line 2 , then the control strategy enforced may not be an optimum control strategy. A better control strategy can be enforced to improve the performance. In addition, if there is no control strategy that can provide reference line 3 below reference line 2, then it can be concluded that: 1) FCFS may be the best control strategy with less information requirement at RF level for which reference line 2 has been drawn and 2) there is no positive absolute contribution of information system for a given superior control strategy. The information system can only be helpful in managing the RF, but it may not have direct contribution in improving the performance of superior control strategy.

Furthermore, makespan performance below reference line 3 represents a condition where $\mathrm{RF}$, control strategy, and information system will have a combined positive contribution in improving the FMS performance. This performance below reference line 3 will be due to synchronization between all the operating parameters of the FMS. The FMS is always expected to have a performance below reference line 3 .

The decision maker can identify the suitable corrective steps needed when the performance of the FMS falls above reference line 3 , reference line 2 , and reference line 1 , respectively. When performance falls below reference line 3, then Taguchi's method can be used to analyze the system. 


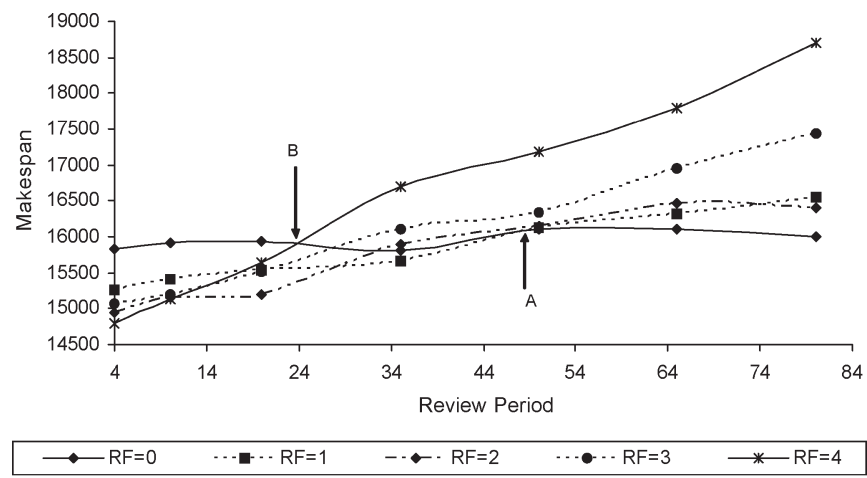

Fig. 3. Impact of different sizes of RP on makespan performance at various levels of RF with SPT as SR and MINQ as DR.

For a given level of RF and a control strategy, the performance of FMS also depends on the information system (RP size). It can be seen in Fig. 2 that the increase in RF is beneficial when RP size is small or when it is real-time control. It can be carefully noticed in Fig. 2 that the makespan performances at smaller RPs sometimes outperform real-time control. It can be explained as follows. In real-time control, some of the lower priority parts do not have a chance of early processing due to real-time availability of the arrival information of high-priority parts. The higher priority parts are processed first, and the lower priority parts remain waiting in the queue. Later, when these lower priority parts are processed, they create bottlenecks on the machines to reduce the performance. The lower priority parts may have a chance of early processing due to RP-based control and avoid bottlenecks. This suggests that there may be some control strategies that can perform better in RP-based control than in real-time control.

The benefits of RF decrease with the increase in RP size (Fig. 2). The performance deterioration is far more at higher levels of RF and increased size of RP. On noticing higher RP sizes in Fig. 2, it can be seen that the performance deterioration is less at lower levels of RF as compared to higher levels of RF. When RP is 35 units of time, the performance deterioration is much less at $\mathrm{RF}=1$ as compared to $\mathrm{RF}=2$, at $\mathrm{RF}=2$ as compared to $\mathrm{RF}=3$, or at $\mathrm{RF}=3$ as compared to $\mathrm{RF}=4$. When $\mathrm{RP}$ size is higher, the increase in RF may be advantageous up to a certain level (below reference line 3); thereafter, further increase in RF level may become counterproductive (above reference line 3).

The decision maker can tradeoff between the level of RF and the RP size required for a given control strategy. For a given level of RF, a cost-effective RP size (information system) and a control strategy can be identified.

Fig. 3 presents the impact of different sizes of RP on makespan performance at various levels of RF with SPT as SR and MINQ as DR. Fig. 3 clearly shows that as the RF level increases, the makespan performance deteriorates for a given size of RP. In Fig. 3, the line of $\mathrm{RF}=1$ cuts the line of $\mathrm{RF}=0$ at point marked "A" around $\mathrm{RP}=50$. This indicates that $\mathrm{RF}=1$ becomes counterproductive when RP size is more than 50 units of time. The information system should be able to provide RP size of less than 50 units of time to obtain the advantages of
$\mathrm{RF}=1$. It can be said as the upper limit of RP size at $\mathrm{RF}=1$. Fig. 3 shows that the upper limit of RP size reduces with the increase in RF. The upper limit of RP size has been reduced to nearly 24 units of time at $\mathrm{RF}=4$ (marked as point " $\mathrm{B}$ "). This again suggests that the RP size should be reduced with the increase in the RF level. In other words, the information system should be suitably upgraded with the increase in RF. The modeling of RP can guide the FMS designer for trading between the advantages associated with the increase in RF level and the investments required to upgrade the information system.

The above discussion highlights that the control strategies, RF, and RP size (information system) should not be viewed separately as they may lead to erroneous decisions. A combined review of these should be done particularly when FMS is operating below reference line 3 (Fig. 2).

In the above results, it has been assumed that raw materials and machines are always available. The nonavailability of raw materials and machine breakdowns cannot be considered as shop-floor control parameters. The decision maker only uses the status information about raw materials and machine availability to schedule the jobs accordingly. The simulation results show that when RP size is small, the results are comparable with real-time control. Under RP-based control, it is expected that the nonavailability of raw materials and machine breakdown will have similar impact as in the case of real-time control, particularly when RP size is small. However, it may be interesting to know the impact of nonavailability of raw materials and machine breakdown with increasing size of RP. These aspects have been left open for future studies.

Furthermore, the results of simulation suggest that the performance of an FMS depends on the combined effect of RF, control strategy, and information system. The change in the level of one factor may have an impact on the performances of the other factor(s). We studied the factors under Taguchi's method to identify the relative percentage contribution of each factor on the FMS performance. This may help the decision maker to know the relative percentage contribution of each factor at its different levels. The decision maker would like to have a close watch on the critical factors to improve the performance.

\section{B. Analysis Under Taguchi's Method}

Tables IV and V show the detailed ANOVA results of few experiments conducted under Taguchi's method with RF level combinations of $\mathrm{RF}=0$ and $\mathrm{RF}=1$ and $\mathrm{RF}=0$ and $\mathrm{RF}=4$, respectively. For each combination of RF levels, the RP level combinations have been varied as RP $=0$ (real time) and RP $=$ $4 / 35 / 65$. Tables IV and V indicate the values of $F$ and relative percentage contribution $(\% P)$ of FMS factors. The significant effects at 5\% significance level are indicated in bold. It can be seen that all the effects of parameters are significant except in three cases. The percentage errors are also below 15\%, which indicates that all the significant contributing factors have been considered in this paper. Table IV shows that when $\mathrm{RP}=35$, the maximum relative percentage contributions $(\% P)$ are of $\mathrm{RF}$ and SR, and next is of the interaction between RF and RP. This 
TABLE IV

Results of ANOVA Under TAguchi's Method FOR ThreE SETs OF ExPERIMENTS With DiffERENT RP LEVELS

\begin{tabular}{|c|c|c|c|c|c|c|}
\hline \multicolumn{7}{|c|}{ ROUTING FLEXIBILITY LEVELS: $\mathrm{RF}=0$ AND RF $=1$} \\
\hline \multirow[t]{2}{*}{$\begin{array}{l}\text { Factors/ } \\
\text { Interactions }\end{array}$} & \multicolumn{2}{|c|}{$\begin{array}{c}\text { REVIEW-PERIOD } \\
\text { LEVEL: } \\
\text { RP }=0 \text { and } 4\end{array}$} & \multicolumn{2}{|c|}{$\begin{array}{c}\text { REVIEW-PERIOD LEVEL: } \\
\text { RP }=0 \text { and } 35\end{array}$} & \multicolumn{2}{|c|}{$\begin{array}{c}\text { REVIEW-PERIOD } \\
\text { LEVEL: } \\
\text { RP }=0 \text { and } 65\end{array}$} \\
\hline & $\mathrm{F}$ & $\% \mathrm{P}$ & $\mathrm{F}$ & $\% \mathrm{P}$ & $\mathrm{F}$ & $\% \mathrm{P}$ \\
\hline $\mathrm{RF}$ & 115.66 & 33.72 & 5996998.33 & 37.10 & 786.98 & 6.29 \\
\hline SR & 125.57 & 36.42 & 586745.22 & 36.46 & 120487.50 & 10.02 \\
\hline$\overline{\mathrm{DR}}$ & 8.13 & 3.28 & 38317.45 & 4.23 & 192.42 & 1.54 \\
\hline $\mathrm{RP}$ & 11.04 & 1.69 & 9924.62 & 0.62 & 5366.53 & 42.40 \\
\hline RF X SR & 16.79 & 2.86 & 12310.05 & 0.76 & 70.30 & 0.55 \\
\hline RF X DR & 18.77 & 3.28 & 68060.50 & 4.23 & 192.42 & 1.54 \\
\hline RF X RP & 56.69 & 11.75 & 221016.98 & 13.73 & 4544.16 & 35.93 \\
\hline SR X DR & 1.29 & 0.02 & 245.22 & 0.02 & - & 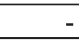 \\
\hline SR X RP & 6.59 & 2.78 & 18022.49 & 1.99 & 91.47 & 0.74 \\
\hline DR X RP & - & - & - & - & 39.464 & 0.30 \\
\hline ERROR & 46.89 & 4.20 & 2793.89 & 0.86 & 18.419 & 0.69 \\
\hline
\end{tabular}

TABLE V

Results of ANOVA Under TAguchi's Method FOR ThreE SETs of ExPERIMENTs With DifFERENT RP LEVELS

\begin{tabular}{|c|c|c|c|c|c|c|}
\hline \multicolumn{7}{|c|}{ ROUTING FLEXIBILITY LEVELS: $\mathrm{RF}=0 \mathrm{AND}$ RF $=4$} \\
\hline \multirow[t]{2}{*}{$\begin{array}{l}\text { Factors/ } \\
\text { Interactions }\end{array}$} & \multicolumn{2}{|c|}{$\begin{array}{c}\text { REVIEW-PERIOD } \\
\text { LEVEL: } \\
\text { RP }=0 \text { and } 4\end{array}$} & \multicolumn{2}{|c|}{$\begin{array}{c}\text { REVIEW-PERIOD LEVEL: } \\
\text { RP }=0 \text { and } 35\end{array}$} & \multicolumn{2}{|c|}{$\begin{array}{c}\text { REVIEW-PERIOD } \\
\text { LEVEL: } \\
\text { RP }=0 \text { and } 65\end{array}$} \\
\hline & $\mathrm{F}$ & $\% \mathrm{P}$ & $\mathrm{F}$ & $\% \mathrm{P}$ & $\mathrm{F}$ & $\% \mathrm{P}$ \\
\hline RF & 988.24 & 55.31 & 15750.25 & 1.70 & 14.83 & 0.01 \\
\hline SR & 380.95 & 21.29 & 71378.02 & 7.70 & 10731.42 & 8.66 \\
\hline DR & 52.23 & 2.87 & 5801.36 & 0.63 & 388.23 & 0.31 \\
\hline RP & 9.49 & 0.48 & 444444.44 & 47.97 & 75462.123 & 60.90 \\
\hline RF X SR & 133.50 & 7.42 & 2288.02 & 0.25 & 701.26 & 0.57 \\
\hline RF X DR & 52.23 & 2.87 & 5801.36 & 0.63 & 388.23 & 0.31 \\
\hline RF X RP & 138.59 & 7.71 & 329476.00 & 35.56 & 29647.73 & 23.93 \\
\hline SR X DR & - & - & 272.25 & 0.03 & - & - \\
\hline SR X RP & 3.04 & 0.11 & 15047.11 & 1.62 & 287.74 & 0.23 \\
\hline DR X RP & 9.10 & 0.45 & - & - & 6.53 & 0.00 \\
\hline ERROR & 3.28 & 1.49 & 7247.58 & 3.91 & 1255.93 & 5.07 \\
\hline
\end{tabular}

signifies that with $\mathrm{RP}=35$, the advantage of $\mathrm{RF}$ is present, and it can be managed by superior SR. The interaction between RF and RP reveals that the performance of RF may be influenced by RP size. When the RP time interval is increased to $\mathrm{RP}=65$, the relative contributions of RF and SR decrease, and the relative contributions of RP and its interaction with RF increase. The objective of RP size is to increase the contributions of control strategy and RF to improve the performance, not to reduce their contributions. The size of RP, which decreases the contributions of RF and control strategy, may deteriorate the performance of the system.

Table $\mathrm{V}$ shows that when RF level is increased to $\mathrm{RF}=4$, the relative contribution of RF has also increased when RP size is small (i.e., $\mathrm{RP}=4$ ). This clearly indicates that there is an advantage of increasing $\mathrm{RF}$ at $\mathrm{RP}=4$. The relative contribution of interaction between RF and SR is also increased, which shows that a superior control strategy may help in obtaining the benefits of RF.

Table VI(a)-(e) shows the detailed results of the relative percentage contributions of RF, RP, interaction between RF and RP, and SR and its interaction with RF. The RF level has been varied from $R F=1$ to $R F=4$ and the $R P$ size from $\mathrm{RP}=4$ to $\mathrm{RP}=65$. In Table $\mathrm{VI}(\mathrm{a})$, it can be seen that the relative contribution of RF decreases with the increase in RP size. The relative contribution on RF is almost vanished when $\mathrm{RP}$ size (periodicity) is large $(\mathrm{RP}=65)$. Hence, there will be no advantage of having $\mathrm{RF}=4$ at $\mathrm{RP}=65$. It can be further seen in Table VI(a) that at $\mathrm{RF}=1$ and $\mathrm{RP}=35$, the relative contribution of RF is significantly present, but after that, the contribution reduces drastically with the increase in RP size. Hence, there is an advantage of having $R F=1$ up to $R P=35$. For $\mathrm{RF}=2$, this advantage of having $\mathrm{RF}$ is reduced to $\mathrm{RP}=20$. For $\mathrm{RF}=3$ and $\mathrm{RF}=4$, this advantage is further reduced to $\mathrm{RP}=10$. Table $\mathrm{VI}(\mathrm{a})$ also indicates that the relative contribution of RF increases with the increase in the RF level when $\mathrm{RP}$ size is small (i.e., $\mathrm{RP}=4$ and $\mathrm{RP}=10$ ). On the contrary, this relative contribution of RF decreases with the increase in RF level when RP size is large. This indicates that the increase in RF level is productive when its relative contribution also increases. The increase in RF level may be counterproductive if its relative contribution decreases.

Table VI(b) shows the relative percentage contributions of RP on the performance of FMS. The relative contribution of RP size is almost negligible (or pooled with errors) when RPs are small. The contribution of RP increases as its size increases. The relative contribution of RP becomes maximum 
TABLE VI

Relative Percentage Contribution of Some Factors Considered for Study Under Taguchi's Method at Various RF and RP LeVels. (a) Percentage Contribution of RF in MaKespan Performance at Various RP and RF Levels Under Taguchi's Method ANOVA

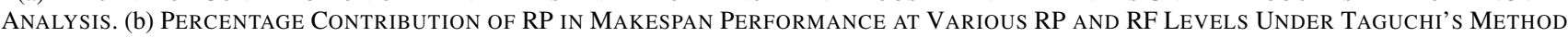
ANOVA ANAlysis. (c) PERCENTAGE CONTRIBUTION OF THE INTERACTION BETWEEN RF AND RP (RFXRP) IN MAKESPAN PERFORMANCE AT Various RP and RF LeVels Under Taguchi's Method ANOVA Analysis. (d) Percentage Contribution of SeQuencing Rule in MaKespan Performance at Various RP and RF LeVels Under Taguchi's Method ANOVA Analysis. (e) Percentage CONTRIBUtion OF THE INTERACTION BETWEen RF AND SEQUENCING RULE (RFXSR) IN MAKESPAN PERFORMANCE AT VARIOUS RP AND RF LEVELS UNDER TAGUCHI'S METHOD ANOVA ANALYSIS

\begin{tabular}{|l|c|c|c|c|c|c|}
\hline $\begin{array}{l}\text { Routing } \\
\text { flexibility } \\
\text { levels }\end{array}$ & $\begin{array}{c}\text { Review } \\
\text { period } \\
\text { levels } \\
(\mathrm{RF}) \downarrow\end{array}$ & $\begin{array}{c}\text { Review } \\
\text { period } \\
\text { levels } \\
\mathrm{RP})\end{array}$ & $\begin{array}{c}\text { Review } \\
\text { period } \\
\text { (RP) }\end{array}$ & $\begin{array}{c}\text { Review } \\
\text { period } \\
\text { (RP) }\end{array}$ & $\begin{array}{c}\text { Review } \\
\text { levels } \\
\text { period } \\
\text { levels }\end{array}$ & $\begin{array}{c}\text { Review } \\
\text { period } \\
\text { levels } \\
(\mathrm{RP})\end{array}$ \\
\hline $\mathrm{RF}=0-1$ & 33.72 & 35.21 & 36.06 & 37.10 & 12.56 & 6.29 \\
\hline $\mathrm{RF}=0-2$ & 43.57 & 36.79 & 25.60 & 15.60 & 2.02 & 2.24 \\
\hline $\mathrm{RF}=0-3$ & 58.41 & 37.91 & 7.37 & 1.64 & 0.67 & 0.80 \\
\hline $\mathrm{RF}=0-4$ & 55.31 & 46.92 & 12.56 & 1.70 & 0.16 & 0.01 \\
\hline
\end{tabular}

(a)

\begin{tabular}{|c|c|c|c|c|c|c|}
\hline $\begin{array}{l}\text { Routing } \\
\text { flexibility } \\
\text { levels } \\
(\mathrm{RF}) \downarrow\end{array}$ & \begin{tabular}{|c|} 
Review \\
period \\
levels \\
$(\mathrm{RP})$ \\
$0-4$ \\
\end{tabular} & \begin{tabular}{|c|} 
Review \\
period \\
levels \\
(RP) \\
$0-10$ \\
\end{tabular} & \begin{tabular}{|c|} 
Review \\
period \\
levels \\
$(\mathrm{RP})$ \\
$0-20$ \\
\end{tabular} & \begin{tabular}{|c}
$\begin{array}{c}\text { Review } \\
\text { period } \\
\text { levels } \\
(\mathrm{RP}) \\
0-35\end{array}$ \\
\end{tabular} & \begin{tabular}{|c|} 
Review \\
period \\
levels \\
(RP) \\
$0-50$ \\
\end{tabular} & $\begin{array}{c}\begin{array}{c}\text { Review } \\
\text { period } \\
\text { levels } \\
\text { (RP) } \\
0-65\end{array} \\
\end{array}$ \\
\hline$R F=0-1$ & 11.75 & 13.16 & 14.88 & 13.73 & 27.56 & 35.93 \\
\hline$R F=0-2$ & 8.19 & 16.16 & 20.85 & 40.23 & 37.62 & 39.07 \\
\hline $\mathrm{RF}=0-3$ & 5.29 & 21.87 & 35.05 & 45.50 & 40.95 & 43.80 \\
\hline $\mathrm{RF}=0-4$ & 7.71 & 16.12 & 31.26 & 35.56 & 44.67 & 23.93 \\
\hline
\end{tabular}

\begin{tabular}{|c|c|c|c|c|c|c|}
\hline $\begin{array}{l}\text { Routing } \\
\text { flexibility } \\
\text { levels } \\
\text { (RF) } \downarrow\end{array}$ & \begin{tabular}{|c|} 
Review \\
period \\
levels \\
(RP) \\
$0-4$
\end{tabular} & \begin{tabular}{|c|}
$\begin{array}{c}\text { Review } \\
\text { period } \\
\text { levels } \\
\text { (RP) } \\
0-10\end{array}$ \\
\end{tabular} & 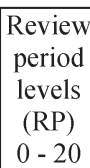 & $\begin{array}{c}\text { Review } \\
\text { period } \\
\text { levels } \\
\text { (RP) } \\
0-35\end{array}$ & 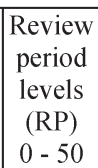 & 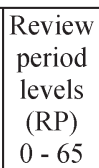 \\
\hline $5=0$ & 1.69 & -5 & 3.19 & 0.62 & 32.72 & 41.21 \\
\hline & - & 26 & 11.69 & 20.85 & 40.62 & 42.40 \\
\hline & - & 7.02 & 25.25 & 32.41 & 43.16 & 45.37 \\
\hline $\mathrm{F}=0$ & 0.48 & 4.95 & 22.73 & 47.97 & 46.41 & 60.90 \\
\hline
\end{tabular}

- Pooled with errors

(b)

\begin{tabular}{|c|c|c|c|c|c|c|}
\hline $\begin{array}{l}\text { Routing } \\
\text { flexibility } \\
\text { levels } \\
\text { (RF) } \downarrow\end{array}$ & 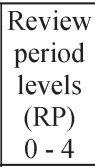 & \begin{tabular}{|c|} 
Review \\
period \\
levels \\
$(\mathrm{RP})$ \\
$0-10$ \\
\end{tabular} & 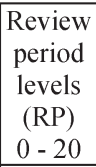 & 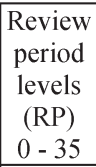 & 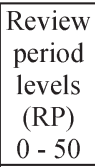 & \begin{tabular}{|c}
$\begin{array}{c}\text { Review } \\
\text { period } \\
\text { levels } \\
(\mathrm{RP}) \\
0-65\end{array}$ \\
\end{tabular} \\
\hline $\mathrm{RF}=0-1$ & 36.42 & 28.51 & 25.30 & 36.46 & 9.28 & 10.02 \\
\hline $\mathrm{RF}=0-2$ & 31.42 & 22.36 & 24.01 & 12.79 & 10.18 & 6.79 \\
\hline $\mathrm{RF}=0-3$ & 23.78 & 15.63 & 13.55 & 11.80 & 7.11 & 3.79 \\
\hline $\mathrm{RF}=0-4$ & 20.41 & 15.27 & 9.21 & 7.70 & 5.2 & 8.66 \\
\hline
\end{tabular}

(d)

(c)

\begin{tabular}{|c|c|c|c|c|c|c|}
\hline $\begin{array}{l}\text { Routing } \\
\text { flexibility } \\
\text { levels } \\
\text { (RF) } \downarrow\end{array}$ & 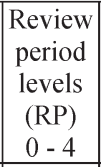 & 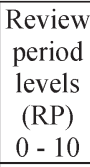 & 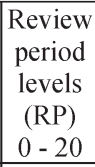 & 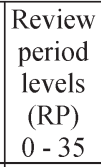 & \begin{tabular}{|c} 
Review \\
period \\
levels \\
(RP) \\
$0-50$ \\
\end{tabular} & \begin{tabular}{|c|} 
Review \\
period \\
levels \\
(RP) \\
$0-65$ \\
\end{tabular} \\
\hline$R F=0-1$ & 2.86 & 2.26 & 2.28 & 0.76 & 0.57 & 0.55 \\
\hline$R F=0-2$ & 9.03 & 6.23 & 4.73 & 2.2 & 1.8 & 1.77 \\
\hline$R F=0-3$ & 8.97 & 5.50 & 2.63 & 1.89 & 1.58 & 0.52 \\
\hline$R F=0-4$ & 7.42 & 5.6 & 1.23 & 0.25 & 0.3 & 0.57 \\
\hline
\end{tabular}

(e)

as compared to other factors when $\mathrm{RP}=65$. It can be understood that the RP is not a direct performance controlling parameter, and hence, it is expected to work as a catalyst to improve the contributions of other controlling factors and not its own contribution. The decision maker can identify suitable RP periodicity such that the relative contribution of RP is negligible or minimum. At higher RF levels, the relative contribution of RP increases more rapidly as compared to lower RF levels. Therefore, the decision maker should be more careful about RP periodicity at a higher RF level.

Table VI(c) shows the relative percentage contributions of the interaction between RF level and RP size. The presence of this interaction shows that the performance of RF is influenced by the RP size and vice versa. The change in the level of one will affect the performance of the other. The increasing contribution of interaction indicates the increasing influence of RP on RF. As increasing RP size has a negative influence on the performance of RF, the increasing contribution of their interaction will deteriorate the performance of RF and, hence, of the system. The decision maker would like to keep the contribution of their interaction as minimum as possible.
Table VI(d) shows the relative percentage contributions of SR. At lower sizes of RP, the relative contributions of SR are significant. The contribution of SR decreases with the increase in size of RP. The results are similar to the contribution of RF. It may be interesting to note that the relative contribution of SR decreases with the increase in the level of RF, particularly when RP size is small. Whereas for the same RP, the relative contribution of RP has been increasing [Table VI(a)]. This indicates that $\mathrm{RF}$ has more dominance in improving the performance as compared to SR when the RP size is small. The decision maker can have better improvement by changing the RF level as compared to changing the SR for a given FMS.

Furthermore, Table VI(e) shows the relative contributions of interaction between SR and RF. The interaction increases with an increase in RF level. This indicates that SR can help in managing RF at higher levels and vice versa. For the decision maker, the selection of a suitable SR is more critical at higher RF levels.

The results of DR show that it does not have much relative percentage contribution at a lower RF level. The maximum contribution of DR has been $13 \%$ at higher RF level, and it 


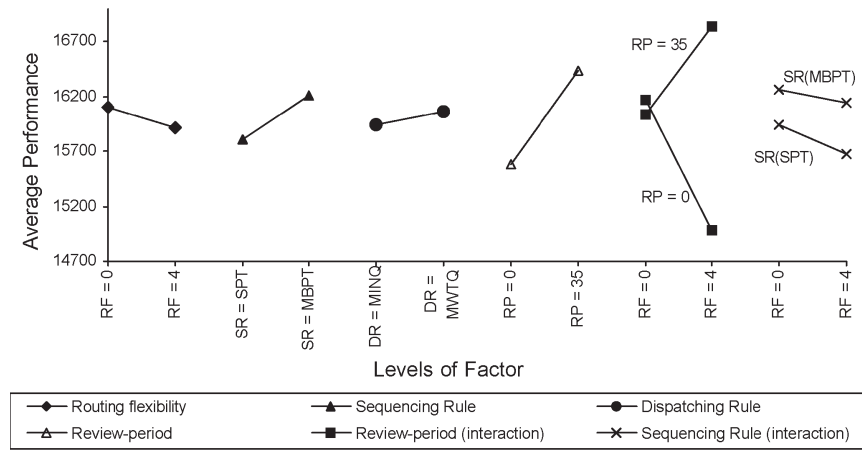

Fig. 4. Average performance of the assumed factors and some interaction at $\mathrm{RP}=0$ and $\mathrm{RP}=35$ and $\mathrm{RF}=0$ and $\mathrm{RF}=4$.

decreases rapidly with the increase in RP size. Hence, detailed results are not presented. Some results for DR can be seen in Tables IV and V. It has been shown that DR interacts with RF.

Fig. 4 shows the average performances of the studied factors and the major interactions under Taguchi's method for RP level combination $\mathrm{RP}=0$ and $\mathrm{RP}=35$ and $\mathrm{RF}$ level combination $\mathrm{RF}=0$ and $\mathrm{RF}=4$. The average performances of the factors help in fulfilling the first objective of Taguchi's study, i.e., to establish the best or the optimum condition for a product or a process. In this paper, the makespan has been considered as a performance measure of a given FMS; therefore, the smaller the makespan, the better the performance. A lower value of makespan refers to a higher performance of the system. The factor levels, which provide a lower value of average performances, are selected to represent the best or optimum conditions for a given FMS. Fig. 4 indicates that factor levels $\mathrm{RF}=4, \mathrm{SR}=\mathrm{SPT}, \mathrm{DR}=\mathrm{MINQ}$, and $\mathrm{RP}=0$ combined together represent the best or optimum operating condition for a given FMS. If this combination of factor levels is one of the combinations in the experiments done for the study, then the optimum value of makespan performance can be taken directly. If not, then the experiment for this combination of factor levels can be performed to obtain the best or optimum value. Furthermore, the response under the optimum conditions can be estimated for its confidence level as the last objective of Taguchi's method analysis. In this paper, our objective was not to find the optimum condition, as it is known that realtime control with a higher RF level will provide the best performance. Hence, the two objectives of Taguchi's method study, i.e., identification of optimum conditions and its response analysis, are not discussed in detail.

Taguchi's method analysis indicates that the decision maker should select the RP level, so that the RF and control strategy (SR and DR) will have a major portion of relative contributions and RP will have a minimum or no contribution on the performance. It also shows that the increase in RF level increases its interaction with RP and control strategy. This means that performance at a higher RF level is more dependent on a suitable control strategy and information system.

\section{ConClusion}

This paper attempts to outline an approach for decision makers/practitioners to have a combined insight on the operating parameters of an FMS. The information system of an FMS is mostly assumed to be real time and has not attracted much attention when analyzing control parameters of an FMS. This paper identifies and analyzes the impact of the information system on RF and control strategies.

When the FMS has a low RF level, then it may not be necessary to have a cost-intensive and information-intensive real-time control. Even at higher flexibility levels, a superior control strategy with smaller RP size can be implemented beneficially. The results indicate that the performance of a given FMS is highly dependent on the level of RF present, RP periodicity (information system), and control strategy enforced. As the flexibility of an FMS system increases, its interactions with the information system and control strategy also increase, i.e., the impacts of information system and control strategy are greater at a higher RF level. A given information system and a control strategy operating as productive at a low RF level may become counterproductive at a higher RF level. Suitable RP size (information system) and control strategy are required to exploit the advantages of a higher RF. A unified analysis of the three operating parameters of an FMS, i.e., RF level, control strategy, and information system, should be undertaken to obtain the real image of an FMS performance.

It is important for the decision maker/practitioner to identify the periodicity of RP according to the RF level present and control strategy enforced to harness the advantages. The simulation experiments under Taguchi's method can help the decision maker to identify the periodicity of an RP. The decision maker can find a tradeoff point between the cost of real-time control and RP periodicity when RF, control strategy, and their interactions are the major relative contributors on the performance. The RP (information system) has to facilitate the control strategy for extracting the benefits from RF. RP (information system) should not have its own direct major relative contribution on the performance of an FMS. If the relative contribution of RP (information system) exceeds the relative contributions of $\mathrm{RF}$ and the control strategy, then the performance of the system may deteriorate. This may help the decision maker to identify the cost-effective, non-real-time, decision-support-oriented, RP-based control for an FMS and periodicity of RP.

\section{REFERENCES}

[1] D. M. Weber and C. L. Moodie, "An intelligent information system for an automated, integrated manufacturing system," J. Manuf. Syst., vol. 8, no. 2, pp. 99-113, Mar. 1989.

[2] P. Higgins and J. Browne, "The monitor in production activity control systems," Prod. Plan. Control, vol. 1, no. 1, pp. 17-26, Jan. 1990.

[3] J. Browne, J. Harhen, and J. Shivnan, Production Management Systems-A CIM Perspective. Reading, MA: Addison-Wesley, 1988, pp. 32-33.

[4] D. Veeramani, B. Bhargava, and M. M. Barash, "Information system architecture for heterarchical control of large FMSs," Comput.-Integr. Manuf. Syst., vol. 6, no. 2, pp. 76-92, May 1993.

[5] K. Patankar and S. Adiga, "Enterprise integration modeling: A review of theory and practice," Comput.-Integr. Manuf. Syst., vol. 8, no. 1, pp. 21-34, Feb. 1995.

[6] H. R. Jorysz and F. B. Vernadat, "CIM-OSA Part 1: Total enterprise modeling and function view," Int. J. Comput. Integr. Manuf., vol. 3, no. 3 , pp. 144-156, Aug. 1990

[7] R. Qiu, R. Wysk, and Q. Xu, "Extended structured adaptive supervisory control model of shop-floor controls for an e-manufacturing system," Int. J. Prod. Res., vol. 41, no. 8, pp. 1605-1620, May 2003. 
[8] J. Pispa and I. V. Eriksson, "Aligning organizations and their information technology infrastructure: How to make information technology support business," Prod. Plan. Control, vol. 14, no. 2, pp. 193-200, Mar. 2003.

[9] T. Park, H. Lee, and H. Lee, "FMS design model with multiple objectives using compromise programming," Int. J. Prod. Res., vol. 39, no. 15, pp. 3513-3528, Oct. 2001.

[10] C. R. Harris, "Modelling the impact of design, tactical, and operational factors on manufacturing system performance," Int. J. Prod. Res., vol. 35, no. 2, pp. 479-499, Feb. 1997.

[11] M. Yurdakul, "Selection of computer-integrated manufacturing technologies using a combined analytic hierarchy process and goal programming model," Robot. Comput.-Integr. Manuf., vol. 20, no. 4, pp. 329-340, Aug. 2004.

[12] D. Duvivier, V. Dhaevers, V. Bachelet, and A. Artiba, "Integrating simulation and optimization of manufacturing system," IEEE Trans. Syst., Man, Cybern. C, Appl. Rev., vol. 33, no. 2, pp. 186-192, May 2003.

[13] Z. Wu and M. X. Weng, "Multiagent scheduling method with earliness and tardiness objectives in flexible job-shops," IEEE Trans. Syst., Man, Cybern. B, Cybern., vol. 35, no. 2, pp. 293-301, Apr. 2005.

[14] H. Cho, J. S. Smith, and R. A. Wysk, "An intelligent workstation controller for integrated planning and scheduling of an FMS cell," Prod. Plan. Control, vol. 8, no. 6, pp. 597-607, Sep. 1997.

[15] G. Liansheng, S. Gang, and W. Shuchun, "Intelligent scheduling model and algorithm for manufacturing," Prod. Plan. Control, vol. 11, no. 3, pp. 234-243, Apr. 2000.

[16] C.-T. Su and Y.-R. Shiue, "Intelligent scheduling controller for shop floor control systems: A hybrid genetic algorithm/decision tree learning approach,” Int. J. Prod. Res., vol. 41, no. 12, pp. 2619-2641, Aug. 2003.

[17] Z. M. Wu, "Modelling and simulation of an intelligent flexible manufacturing system via high-level object Petri nets (HLOPN)," Int. J. Prod. Res., vol. 43, no. 7, pp. 1443-1463, Apr. 2005.

[18] A. Mcafee, "The impact of enterprise information technology adoption on operational performance: An empirical investigation," Prod. Oper. Manag., vol. 11, no. 1, pp. 33-53, Spring 2002.

[19] R. Montazemi and G. J. Miltenburg, "A modeling tool for analysing the information requirement of computer integrated manufacturing system," INFOR, vol. 29, no. 3, pp. 240-250, Aug. 1991.

[20] M. Harzallah and F. Vernadat, "IT-based competency modeling and management: From theory to practice in enterprise engineering and operations," Comput. Ind., vol. 48, no. 2, pp. 157-179, Jun. 2002.

[21] Y. L. Quéré, M. Sevaux, C. Tahon, and D. Trentesaux, "Reactive scheduling of complex system maintenance in a cooperative environment with communication times," IEEE Trans. Syst., Man, Cybern. C, Appl. Rev., vol. 33, no. 2, pp. 225-234, May 2003.

[22] J. A. Harding, B. Yu, and K. Popplewell, "Information modelling: An integration of views of a manufacturing enterprise," Int. J. Prod. Res., vol. 37, no. 12, pp. 2777-2792, Aug. 1999.

[23] E. R. Wainwright and K. Ridgway, "The application of GRAI as a framework for manufacturing strategy process," in Proc. Factory-Advanced Factory Automation, Oct. 1994, pp. 294-301.

[24] F. T. S. Chan and H. K. Chan, "Dynamic scheduling for a flexible manufacturing system-The pre-emptive approach," Int. J. Adv. Manuf. Technol., vol. 17, no. 10, pp. 760-768, 2001.

[25] J. Slomp and W. H. M. Zijm, "A manufacturing planning and control system for a flexible manufacturing system," Robot. Comput.-Integr. Manuf., vol. 10 , no. $1 / 2$, pp. 109-114, Feb. 1993.

[26] L. K. Church and R. Uzsoy, "Analysis of periodic and event-driven rescheduling policies in dynamic shops," Int. J. Comput. Integr. Manuf., vol. 5, no. 3, pp. 153-163, Aug. 1992.

[27] M. H. Kim and Y. D. Kim, "Simulation-based real-time scheduling in a flexible manufacturing systems," J. Manuf. Syst., vol. 13, no. 2, pp. 85-93, Mar. 1994.

[28] M. Matsui, K. Kaneda, and K. Kanbara, "Optimal control of a job-shop production system: Periodic versus dynamic type," Int. J. Prod. Res., vol. 38, no. 13, pp. 2951-2966, Sep. 2000.

[29] R. Shafaei and P. Brunn, "Workshop scheduling using practical (inaccurate) data-Part 1: The performance of heuristic scheduling rules in a dynamic job-shop environment using a rolling time horizon approach," Int. J. Prod. Res., vol. 37, no. 17, pp. 3913-3925, Nov. 1999.

[30] I. Miguel and Q. Shen, "Exhibiting the behaviour of time-delayed systems via an extension to qualitative simulation," IEEE Trans. Syst., Man, Cybern. A, Syst., Humans, vol. 35, no. 2, pp. 298-305, Mar. 2005.

[31] P. Shewchuk and C. L. Moodie, "Flexibility and manufacturing system design: An experimental investigation," Int. J. Prod. Res., vol. 38, no. 8, pp. 1801-1822, 2000.
[32] B. R. Sarker, S. Krishnamurthy, and S. G. Kuthethur, "A survey and critical review of flexibility measures in manufacturing systems," Prod. Plan. Control, vol. 5, no. 6, pp. 512-523, 1994.

[33] B. D. Dubois, K. Rathmill, P. Sethi, and K. E. Steke, "Classification of flexible manufacturing systems," FMS Mag., vol. 2, no. 2, pp. 114-117, Apr. 1984.

[34] R. Rachamadugu and K. E. Stecke, "Classification and review of FMS scheduling procedures," Prod. Plan. Control, vol. 5, no. 1, pp. 2-20, 1994.

[35] C. Kwak and Y. Yih, "Statistical analysis of factors influencing the performance of the timeout-based testing model," Int. J. Prod. Res., vol. 41, no. 5, pp. 1033-1044, 2003.

[36] Y. Chen, J. Tang, R. Y. K. Fung, and Z. Ren, "Fuzzy regression-based mathematical programming model for quality function deployment," Int. J. Prod. Res., vol. 42, no. 5, pp. 1009-1027, Mar. 2004.

[37] R. Narasimhan and A. Das, "An empirical examination of sourcing's role in developing manufacturing flexibilities," Int. J. Prod. Res., vol. 38, no. 4, pp. 875-893, Mar. 2000

[38] R. K. Roy, A Primer on Taguchi Method. New York: Van Nostrand Reinhold, 1990.

[39] S. Phadke, Quality Engineering Using Robust Design. Englewood Cliffs, NJ: Prentice-Hall, 1989.

[40] T. P. Bagchi, Taguchi Methods Explained-Practical Steps to Robust Design. New Delhi, India: Prentice-Hall India, 1993.

[41] N. Logothetis and H. P. Wynn, Quality Through Design. Oxford, U.K.: Clarendon, 1989.

[42] H. Darabi, M. A. Jafari, and S. S. Manapure, "Finite automata decomposition for flexible manufacturing systems control and scheduling," IEEE Trans. Syst., Man, Cybern. C, Appl. Rev., vol. 33, no. 2, pp. 168-175, May 2003.

[43] F. T. S. Chan, "Effects of routing flexibility on a flexible manufacturing system," Int. J. Comput. Integr. Manuf., vol. 14, no. 5, pp. 431-445, Sept./Oct. 2001.

[44] B. Shnits, J. Rubinovittz, and D. Sinreich, "Multi-criteria dynamic scheduling methodology for controlling a flexible manufacturing system," Int. J. Prod. Res., vol. 42, no. 17, pp. 3457-3472, Sep. 2004.

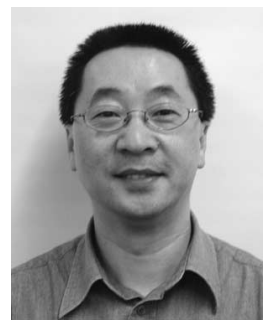

Felix T. S. Chan received the B.Sc. degree (with first class honors) in mechanical engineering from Brighton Polytechnic (now Brighton University), Brighton, U.K., and the Ph.D. degree in manufacturing engineering from the Imperial College of Science and Technology, University of London, London, U.K.

He was a Research Fellow for two years with the Department of Design, Manufacture and Engineering Management, University of Strathclyde, Glasgow, U.K. Prior to joining the University of Hong Kong, Kowloon, in 1996, he was a Senior Lecturer with the School of Manufacturing and Mechanical Engineering, University of South Australia, Adelaide, Australia. He is currently an Associate Professor with the Department of Industrial and Manufacturing Systems Engineering, University of Hong Kong. He has published three book chapters, more than 130 referred international journal papers, and 160 peer-reviewed international conference papers. His current research interests are in logistics and supply chain management, distribution coordination, systems modeling and simulation, and supplier selection.

Dr. Chan is a Senior Member of the Society of Manufacturing Engineers and a Chartered Member of the Chartered Institute of Logistics and Transport in Hong Kong. 


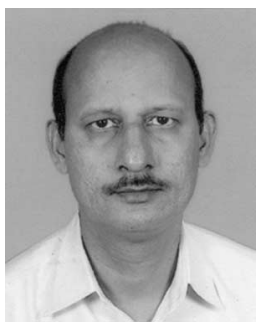

Rajat Bhagwat received the B.E. degree (Hons.) in mechanical engineering and the Master's degree in production and industrial engineering from J. N. V. University, Jodhpur, India, and the Ph.D. degree in industrial engineering from the Indian Institute of Technology-Delhi, New Delhi.

$\mathrm{He}$ has been a Lecturer and a Reader with J. N. V. University and a Research Assistant with the University of Hong Kong, Kowloon. He has experience in simulation modeling and programming of software such as witness and arena. He has worked in industrial projects in the area of production, planning and control, capacity expansion, and layout planning. He has taught many subjects related to production and industrial engineering to undergraduate and postgraduate students. He is the author of a number of publications in international journals and conferences. His research interest is in simulation and control of flexible manufacturing systems.

Dr. Bhagwat is a Life Member of the Indian Society for Technical Education. He has been awarded a postdoctoral fellowship by the University of Bordeaux, Bordeaux, France.

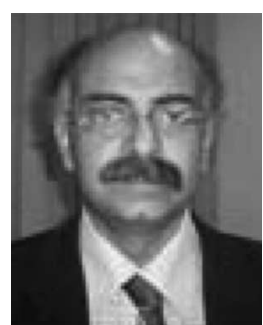

S. Wadhwa received the Ph.D. degree from University College, Galway, Ireland, while working on an ESPRIT project on the Integration of Robots in Computer-Integrated Manufacturing.

After receiving the Ph.D. degree, he was with Digital Equipment Corporation, a U.S. multinational company, where he worked in the area of knowledge engineering and contributed to another ESPRIT project on Integrated Manufacturing Planning and Control Systems. In 1990, he joined the Department of Mechanical Engineering, Indian Institute of Technology-Delhi, New Delhi, where he is currently a Professor. He has contributed extensively to the development of generalized simulators and expert systems to assist the evaluation of flexible assembly systems. He has more than 100 publications in international journals and conferences and has coauthored a chapter of a book edited by U. Rembold. His research and consultancy areas focus on FMS, decision systems, simulations, AI in manufacturing, ERP, and logistics.

Dr. Wadhwa is a Chartered Engineer and a European Engineer. 